\title{
Suramérica en la transición histórico-espacial mundial: una propuesta de periodización del giro nacional-popular (1999-2018)
}

South America in the world historical spatial transition: A proposal for the periodization of the national-popular turn (1999-2018)

\section{Gabriel E. Merino}

Instituto de Investigaciones en Humanidades y Ciencias Sociales - Universidad Nacional de La Plata (IdIHCS-UNLP) - CONICET, Argentina

gmerino@fahce.unlp.edu.ar

\author{
Soledad Stoessel \\ Instituto de Investigaciones en Humanidades y Ciencias \\ Sociales (IdIHCS-UNLP) - CONICET, Argentina \\ soledad.sto@gmail.com
}

\begin{abstract}
RESUMEN:
El presente escrito se propone elaborar una periodización de la transición histórico-espacial en Suramérica desde fines del siglo pasado hasta la actualidad. En términos metodológicos, esta propuesta de periodización se basa en un análisis de coyunturas críticas a nivel regional durante las cuales se produce una medición de fuerzas entre proyectos políticos estratégicos. A partir de la identificación de estas coyunturas, se definen cinco grandes momentos: 1) el quiebre de la hegemonía del proyecto financiero neoliberal y unipolar entre octubre de 1998 y abril de 2002;2) la construcción de Alternativas: el desarrollo del eje Atlántico y el "No al ALCA" entre abril de 2002 y noviembre de 2005; 3) el avance estratégico del nacionalismo popular latinoamericano en una clave postneoliberal y de la continentalidad suramericana entre noviembre de 2005 y 2011;4) la aparición de la Alianza Pacífico, el reinicio de la ofensiva unipolar, el estancamiento del regionalismo autónomo y el debilitamiento del nacionalismo popular entre abril de 2011 y octubre de 2015; 5) la embestida del proyecto financiero, neoliberal y unipolar y el reflujo de las fuerzas nacionalespopulares en América Latina entre octubre de 2015 y junio de 2018.
\end{abstract}

Palabras clave: América Latina, Transición histórica, Coyunturas críticas, Posneoliberalismo, Proyectos políticos estratégicos.

\begin{abstract}
:
The aim of this paper is to elaborate a periodization of the historical-spatial transition in South America from the end of the last century to the present day. In methodological terms, this periodization proposal is based on an analysis of critical junctures at the regional level during which there is a measurement of forces among strategic political projects. The identification of these conjunctures allows us to define five significant moments: 1) the collapse of the neoliberal and unipolar financial project between October 1998 and April 2002;2) the construction of alternatives: the development of the Atlantic Axis and the "No al ALCA" [No to ALCA] between April 2002 and November 2005; 3) the strategic advance of Latin American popular nationalism in a postneoliberal and South American continental key between November 2005 and 2011; 4) the emergence of the Pacific Alliance, the resumption of the unipolar offensive, the stagnation of autonomous regionalism and the weakening of popular nationalism between April 2011 and October 2015; 5) the onslaught of the financial, neoliberal and unipolar project and the reflux of nationalpopular forces in Latin America between October 2015 and June 2018.
\end{abstract}

KEYwORDS: Latin America, Historical transition, Critical juntures, Posneoliberalism, Stategic political projects.

Desde la asunción de Hugo Chávez en Venezuela comienza una nueva etapa histórica en la región latinoamericana. Este período fue caracterizado de distintas maneras: como una etapa "posneoliberal", como "un giro a la izquierda" (Stoessel, 2014), como un momento de gobiernos "progresistas" ("marea rosa”), de retorno de los "populismos” y de reemergencias de los nacionalismos populares. Estos procesos pusieron 
en práctica un regionalismo autonomista, como perspectiva dominante en materia de integración regional, y un alejamiento geopolítico de "Occidente" en general, y de Estados Unidos en particular, a partir del distanciamiento del Consenso de Washington. Evidentemente, esto no fue así en todos los países; solo ocurrió en aquellos en donde se constituyeron fuerzas político-sociales antineoliberales que se convirtieron en poder gubernamental. Además, ello varió de acuerdo a las características de estos gobiernos y las correlaciones de fuerzas existentes en cada país.

Si utilizamos ciertas categorías vinculadas al pensamiento de Dussel (2009), podríamos hablar de un giro popular, que se expresa parcialmente en algunos procesos políticos de la región, siendo el pueblo un proceso constitutivo a partir de la escisión de los oprimidos - "la comunidad de víctimas"- del bloque histórico en el poder, y de lo popular como la expresión fenomenológica del pueblo. $\mathrm{Y}$ es un giro nacional, en el sentido de reclamar y reconstruir mayores grados de soberanía a través del fortalecimiento de los factores internos de producción, el control de los mercados, y el aumento de los márgenes de participación estatal -en detrimento de los capitales concentrados transnacionales y locales- en los ingresos generados, que luego serán redistribuidos prioritariamente hacia los sectores más perjudicados (Thwaites Rey, 2009). El giro nacional también se expresa en la construcción de una nueva territorialidad, en tanto el territorio implica apropiación, ejercicio de dominio y control de una porción de la superficie terrestre, pertenencia y proyectos de una sociedad. Se trata de un espacio apropiado, delimitado y dotado de identidad, atravesado por relaciones sociales de producción y reproducción de vida (Merino, 2011).

El presente escrito se propone elaborar una periodización de la transición histórico-espacial en América Latina desde fines del siglo pasado hasta nuestros días. Se enfatizará en la dimensión de horizonte compartido de los procesos políticos latinoamericanos, más que en sus especificidades. En términos metodológicos, esta propuesta de periodización se basa en un análisis de coyunturas críticas en la escala regional, durante las cuales se producen distintas mediciones de fuerzas entre proyectos políticos estratégicos. Recuperamos el concepto de coyuntura crítica proveniente de los estudios politológicos para dar cuenta de aquellos sucesos que abren un conjunto de opciones para transformar las relaciones políticas, patrones institucionales y modelos de desarrollo que se han normalizado y estabilizado a lo largo del tiempo (Capoccia y Kelemen, 2007). García Linera (2009) habla de aquélla como punto de bifurcación, es decir, como un acontecimiento sociopolítico que deriva en "generalizados momentos de lucha", que revelan nítidamente cuáles son las fuerzas en pugna y sus capacidades y al mismo tiempo la resuelven en favor de una u otra fuerza. Por lo general, las coyunturas críticas se establecen como momentos destituyentes y fundacionales para el inicio de nuevas formas institucionales y políticas duraderas en las que la capacidad agencial de las fuerzas contrincantes se potencia en relación a los períodos de "equilibrio". Los efectos de sus decisiones son determinantes en el reforzamiento de dichas novedosas formas y en la institución de legados (Collier y Collier, 1991). No obstante, las coyunturas críticas pueden ser más o menos fundacionales de acuerdo al modo en que devienen las correlaciones entre las fuerzas sociales y políticas en distintas escalas (local, regional, mundial). Metodológicamente, surgen dificultades a la hora de establecer qué hitos pueden identificarse como puntos de bifurcación o coyunturas críticas en la medida en que, si bien éstas tienen un correlato empírico, constituyen un constructo analítico de acuerdo a la problemática que se estuviere analizando. En nuestro caso de análisis identificaremos coyunturas críticas en relación a acontecimientos que trastocaron las correlaciones entre las fuerzas nacionales-populares y fuerzas afines al proyecto neoliberal-financiero (PNF) desde los años noventa hasta la actualidad.

A partir de allí se definen cinco grandes momentos: 1) el quiebre de la hegemonía del PNF y unipolar entre octubre de 1998 y abril de 2002; 2) la construcción de alternativas: el desarrollo del eje Atlántico y el "No al ALCA" entre abril de 2002 y noviembre de 2005; 3) el avance estratégico del nacionalismo popular latinoamericano en una clave postneoliberal, y de la continentalidad suramericana entre noviembre de 2005 y 2011; 4) la aparición de la Alianza Pacífico, el reinicio de la ofensiva unipolar, el estancamiento del regionalismo autónomo y el debilitamiento del nacionalismo popular entre abril de 2011 y octubre de 2015; 
5) la embestida del PNF y el reflujo de las fuerzas nacionales-populares en América Latina entre octubre de 2015 y junio de 2018.

\section{MOMENTOS, COYUNTURAS CRÍTICAS Y TRANSICIONES HISTÓRICAS}

La nueva etapa que se abre en América Latina a inicios del presente siglo está vinculada a la transición histórica mundial y a un momento de ésta en el cual se produce una reacción al unipolarismo angloamericano y al avance global del PNF. Dentro de dicha transición, a partir de 1999 podemos observar el momento germinal de la situación actual de multipolaridad relativa (Narodowski y Merino, 2015; Merino, 2016), es decir, la forma geopolítica de la transición en el marco de una crisis del capitalismo global. Es el año en que en Estados Unidos comienzan a profundizarse las tensiones internas entre globalistas y americanistas. Es el año en que Alemania y Francia, junto con sus aliados europeos, avanzan en la constitución del euro para fortalecer el bloque de poder europeo continental y obtener un mayor margen de autonomía respecto a Washington. Esto provocará una tensión que se expresará claramente en la guerra de Irak, propiciada por Estados Unidos y el Reino Unido, y rechazada por Francia, Alemania y Rusia, con importantes intereses en este país (Harvey, 2003, p. 32). Además, 1999 es el año que -el 31 de diciembre, tras la dimisión de Boris Yeltsin- ve llegar a la presidencia de Rusia a Vladímir Putin (cargo que meses más tarde confirmaría electoramente de forma contundente), hecho que expresa el renacer del "poder ruso". Es, a su vez, el año en que China, el gigante oriental que creció vertiginosamente durante veinte años (Arrighi, 2007), asume formalmente la soberanía de Macao (colonia portuguesa), luego de que en 1997 recuperara la de Hong Kong (colonia británica). Ese año es bombardeada su embajada en Belgrado por parte de Estados Unidos, lo que provoca fuertes tensiones.

La asunción de Hugo Chávez a la presidencia de Venezuela produce la primera grieta para el proyecto neoliberal y el Consenso de Washington en América Latina y el Caribe más allá de Cuba. Por otra parte, a meses de comenzar 1999, el 29 de noviembre de 1998, el papa Juan Pablo II expide el jubileo 2000. En el mismo se propone la condonación de la deuda externa a países pobres y en desarrollo, en sus tres formas principales de endeudamiento: la contraída con los bancos comerciales, con los gobiernos y con las entidades multilaterales de crédito (Fondo Monetario Internacional, Banco Mundial, Banco Interamericano de Desarrollo, etc.). Según el Jubileo, la deuda es inmoral, ilegítima e impagable. Esta propuesta está en el marco de la lucha contra el "capitalismo salvaje", que el Vaticano viene desarrollando desde la caída del muro de Berlín para diferenciarse del neoliberalismo de cuño anglosajón y su avance global amparado en el "There is no alternative" de Margarete Thatcher. A partir de allí, muchos sectores de la Iglesia Católica en América Latina serán cada vez más protagonistas en la conformación de un discurso contra ese capitalismo y el PNF, e incluso promoverán la construcción de espacios de confluencia para elaborar proyectos políticos alternativos.

También en 1999 devalúa su moneda Brasil, luego de la ola de devaluaciones en los países "emergentes", que se inicia en 1997 con el estallido de la crisis del sudeste asiático y que fue el puntapié inicial para el avance del capital transnacional sobre la periferia, de fuertes adquisiciones (centralización del capital) y debilitamiento de los actores económicos locales de los respectivos países “emergentes”. En Argentina se fracturan los grupos y clases dominantes, y comienzan las luchas entre dos configuraciones: por un lado, quienes proponen dolarizar la economía, establecer el Área de Libre Comercio de la Américas (ALCA) promovida por los Estados Unidos para subordinar a Suramérica a su área económica, y profundizar el programa económico neoliberal (privatizar los bancos públicos, ajustar más los salarios, imponer la ley de flexibilización laboral). Por otro lado, están quienes en sintonía con lo acontecido en Brasil comienzan a debatir la necesidad de devaluar el peso, fortalecer el MERCOSUR y salir del proyecto neoliberal, agrupados en el Movimiento Productivo Argentino (MPA). A su vez, la resistencia popular al neoliberalismo crece a medida que se agudiza la crisis económica, aumenta el desempleo y se dispara la pobreza.

Latinoamericana retomó a principios de siglo, una vez más, distintos senderos para romper o al menos atenuar su situación de dependencia, su división política y su consecuente condición de periferia. Este 
fenómeno ha estado atado al cambio clave, mencionado en la introducción, que se produce a partir de fines de los años noventa. Cada vez que se producen escenarios de transición histórico-espacial del sistema mundial se abren condiciones para que reemerjan, en la región y en las periferias en general -allí donde existe cierto grado de desarrollo de las fuerzas subjetivas-, los movimientos nacionales, populares y latinoamericanos. Estos movimientos, de naturaleza heterogénea y dominados cada uno por distintos proyectos estratégicos, al expresarse contradictoriamente a través de distintos gobiernos en el Estado, dieron lugar a procesos transformadores, de ruptura con la hegemonía neoliberal. Cabe mencionar que también estas transiciones están derivando, en contraposición a los procesos mencionados, en reacciones conservadoras-autoritarias por parte del conjunto de los poderes/grupos dominantes tradicionales (o determinadas fracciones dentro de estos), como puede ser el caso de Jair Bolsonaro en Brasil y sus formas pseudofascistas, que sobre el final desarrollaremos.

Los momentos de dicha transición se hacen visibles, entre otras formas, en los cambios institucionales, entre los que se incluyen los acuerdos en materia de integración regional, los cuales son fundamentales, ya que la división político-estratégica de la región es una de las determinaciones fundamentales de su carácter de periferia subdesarrollada. Los cambios institucionales objetivan transformaciones que indican un cambio en las correlaciones de fuerzas en el Estado y nos permiten observar qué fuerzas avanzan y cuáles retroceden, qué proyectos de sociedad influyen en mayor o menor medida en el Estado. En ese sentido, el posneoliberalismo no se trata de una mera posibilidad estructural (y por momentos fantasmagórica), sino de aperturas y clausuras de las correlaciones de fuerza y de las “selectividades estratégicas" (Jessop, 2017) que atraviesan el terreno estatal en un momento determinado. Si seguimos a este autor, las selectividades estratégicas se refieren a aquellos patrones, elementos y aspectos que atraviesan al terreno estatal, y que operan como restricciones al mismo tiempo que como oportunidades para la acción política. Los actores sociales elaboran análisis estratégicos del contexto para escoger cursos de acción de acuerdo a las selectividades que atraviesan al Estado, los nodos y redes de poder que lo configuran y las estrategias de otros actores sociales, ya sea para sortearlas, modificarlas o emplearlas a su favor. El Estado, así, aparece como el terreno donde se expresan los dilemas estratégicos de los actores. De acuerdo a las coyunturas políticas específicas y a las cambiantes correlaciones de fuerzas, dicho terreno será más o menos propicio para lograr que determinadas estrategias sean más efectivas que otras y para que determinados actores sociales tengan mayor injerencia política que otros.

\section{Momento 1 (octubre de 1998 a abril-octubre de 2002): el quiebre de la hegemonía del proyecto financiero neoliberal y unipolar}

La asunción de Chávez el 2 de febrero de 1999, luego de la victoria electoral del 8 de noviembre de 1998, constituye el primer quiebre a nivel gubernamental con el neoliberalismo. En efecto, la promesa de la campaña de 1998 había sido la refundación del Estado en una clave antineoliberal y socialista, y el reemplazo constitucional por medio del llamado a una asamblea constituyente. Esta asunción presidencial constituye una coyuntura crítica no sólo a nivel nacional sino que abre una serie de opciones de rupturas políticas a nivel regional. Sin lugar a dudas, la insurrección zapatista del sur de México conmocionó a América Latina y el mundo, y marcó una profunda resistencia al Consenso de Washington, al neoliberalismo y a la expansión unipolar que significó el TLCAN. Pero, de hecho, el TLCAN se firmó y a pesar de la conmoción no fue detenido el proyecto imperial, aunque sí se oxigenaron las resistencias populares de la región e incluso del mundo. También, el chavismo emerge como un producto de la acumulación de luchas de resistencia al neoliberalismo, que aparecen con total contundencia en el Caracazo de 1989 y continúan durante una década. Pero es a partir de la asunción de fuerzas nacionales y populares en el gobierno del Estado que el poder instituyente logra establecer una nueva realidad estatal transformadora, lo que posibilita una salida más o 
menos popular -según la articulación político-social que se estableciere y la correlación de fuerzas existentea la crisis de la hegemonía neoliberal.

La Guerra del Agua en Bolivia en el año 2000, en la que una enorme masa popular asciende a las luchas políticas oponiéndose a la privatización de ese recurso clave y a las consecuencias sociales que ello traería, pone de manifiesto el resquebrajamiento de la hegemonía neoliberal en dicho país y el comienzo de la articulación de un nuevo bloque popular. Dicho acontecimiento es parte de la coyuntura crítica inaugurada con la asunción de Chávez al poder. Como señala García Linera (2009), allí se develan las contradicciones que dan inicio a la crisis del Estado bajo el neoliberalismo y comienza a configurarse lo que luego devendrá en el "evismo" 1 .

En Ecuador, por su parte, el fin del siglo también se vio convulsionado. Desde 1997 al 2005 ningún gobierno electo por el voto popular pudo finalizar su mandato, como consecuencia de golpes institucionales, destituciones presidenciales por la vía parlamentaria y movilizaciones sociales; se sucedieron así cinco gobiernos. Para 1999 la economía ecuatoriana se encontraba en una profunda crisis. El sistema financiero ecuatoriano estaba quebrado, debido, entre otros elementos, a la promulgación de la Ley General de Instituciones del Sistema Financiero promovida por el FMI durante el gobierno de Durán Ballén. Dicha normativa protegía las prácticas de la banca privada. El gobierno decidió inyectarla de recursos con el objeto de evitar su quiebra y para ello incautó los depósitos bancarios de los agentes privados y la ciudadanía a fin de salvar el sistema financiero (el conocido "feriado bancario" consistió en el congelamiento durante cinco días de los ahorros de los ciudadanos y de toda operación financiera, al igual que el "corralito" en Argentina). Esta drástica medida vino acompañada de recortes en los subsidios de gas doméstico y electricidad, y de un aumento tarifario de un $400 \%$. Como última política, el gobierno de Mahuad, asesorado por economistas argentinos de la Fundación Mediterránea creada por Cavallo -el artífice del plan de convertibilidad en Argentina- decidió dolarizar la economía ecuatoriana, ya que, para diciembre de 1999, la inflación anual había llegado a un 60,7 \%. En este contexto emergieron distintos focos de protesta, en lo fundamental protagonizados por el movimiento indígena, estudiantil y sectores populares.

Como parte de la ola de crisis en la periferia del capitalismo global (Sudeste asiático en 1997, Rusia 1998, Brasil 1999, Turquía 2001), en 2001 se desata la crisis en Argentina, luego de cuatro años de recesión económica y crecientes resistencias al proyecto financiero neoliberal y al bloque de poder que lo sostiene. Durante ese ciclo, las fuerzas dominantes buscaron avanzar hacia la profundización neoliberal con la privatización de los bancos públicos que quedaban en pie, el avance hacia el ALCA, la privatización del cobro de impuestos y una posible dolarización completa de la economía para salir del plan de convertibilidad (aunque allí había diferencias entre globalistas y americanistas). En ese escenario, se expresa el ascenso de un contradictorio bloque nacional productivo, con un programa neodesarrollista articulado por el MPA, que en su cúspide contiene a los grupos económicos locales y la burguesía local encabezados por la Unión Industrial Argentina, a cuadros neodesarrollistas como Roberto Lavagna, y a Eduardo Duhalde y Raúl Alfonsín como referentes de esta fuerza al interior del peronismo y del radicalismo respectivamente, además del FREPASO (Merino, 2015). El 19 y 20 de diciembre implosionan en Argentina el sistema político y su modelo de acumulación, y se suceden una serie de presidentes, hasta que finalmente en enero de 2002 asume como presidente interino el senador y referente del MPA Eduardo Duhalde, lo que da inicio a la transición que desembocará en la elección que permitió a Néstor Kirchner llegar al poder.

\section{Momento 2 (abril-octubre de 2002 y noviembre de 2005): del desarrollo del eje Atlántico- caribeño al "ALCArajo"}

En abril de 2002 se produce otra coyuntura crítica, iniciada también en Venezuela, que marcará un antes y un después en el proceso político regional. El golpe de Estado contra Hugo Chávez, encabezado por uno de los referentes de los sectores dominantes (Pedro Carmona de FEDECAMARAS), que fue 
contestado con una desbordante insurrección popular, protagonizada especialmente por las clases populares trabajadoras de Caracas, junto con el apoyo de grupos de las Fuerzas Armadas. La condena al "golpe de Estado" en Venezuela manifestada por Duhalde en Argentina ${ }^{2}$ también puso de manifiesto la nueva etapa que se abría en la región. En este mismo sentido (aunque con una envergadura mucho menor a la insurrección venezolana), la reacción popular y política a la "masacre en el Puente Pueyrredón" en Argentina (Pinedo, 2009) fue parte de dicha coyuntura crítica -que ya evidenciaba un "cambio de época"-, sumida en una tensión entre el objetivo estratégico de producir un golpe conservador y represivo favorable a las fuerzas que proponían como rumbo la dolarización y el ALCA, y la reacción de otras fuerzas que propugnaban una salida postneoliberal.

El triunfo de Luiz Inácio "Lula" da Silva en Brasil en el mes de octubre de 2002 ofrece más elementos para dar cauce al quiebre de la hegemonía del proyecto financiero neoliberal y unipolar dada la importancia vital que tiene Brasil para la región (Da Silva Guevara, 2018): representa casi la mitad de Suramérica en cuanto a población, territorio y PIB. La llegada de Lula al gobierno del gigante suramericano se dio a través de una alianza entre clases populares y sectores de izquierda con parte de la burguesía nacional y capas de la burocracia y de la intelectualidad neodesarrollista. La articulación nacional-popular neodesarrollista en Brasil significó la influencia en el Estado de un conjunto de grupos sociales subordinados que se tradujeron en medidas favorables a la inclusión social, a fortalecer el mercado interno y a recuperar grados relativos de soberanía, a pesar de compartir el poder con fuerzas neoliberales y conservadoras (por lo menos hasta 2006) (Merino, 2018b).

Con el triunfo de Néstor Kirchner el 27 de abril de 2003, apoyado por Duhalde y las fuerzas ligadas al MPA, se termina de definir en términos institucionales en Argentina el cambio en las correlaciones de fuerzas en el Estado que comienza en diciembre de 2001. Desde ese momento, la coyuntura crítica abierta un año atrás por el golpe de Estado a Chávez se cierra. A partir de allí comienza a configurarse un eje atlántico-caribeño conformado por Argentina, Brasil, Venezuela y Cuba con suficiente masa crítica de poder para conformar, embrionariamente y de forma al menos defensiva, un polo de poder regional.

Tanto la cumbre del MERCOSUR de junio de 2003 como la de diciembre manifestaron cambios respecto a la concepción de la integración regional. Un retorno a ideas propias de un regionalismo autónomo, vinculado a las tradiciones nacional-desarrollistas, en detrimento del regionalismo abierto de los años noventa en sintonía con el programa neoliberal, se hizo patente (Kan, 2015) ${ }^{3}$. En principio, se refuerza la necesidad de perfeccionamiento de la Unión Aduanera con miras a la formación del Mercado Común. A su vez, se acuerda priorizar la dimensión social del MERCOSUR. También asistió Hugo Chávez a la cumbre de Asunción y realizó el pedido formal de incorporación como miembro del MERCOSUR. Además, se propuso considerar el desarrollo de un parlamento del MERCOSUR ${ }^{4}$.

Mientras que el Cono Sur avanzaba en esta agenda progresista, la región andina aún estaba sumida en los trazos neoliberales. En Ecuador, el gobierno electo de Lucio Gutiérrez, quien asumió en 2003 en alianza con la Confederación de Nacionalidades Indígenas del Ecuador (CONAIE), la organización indígena más gravitante de Ecuador, prontamente viró la agenda económico-política propuesta durante la campaña electoral, y retomó los postulados del neoliberalismo que profundizarían el ciclo de ajuste estructural. Buena parte de la CONAIE y Pachakutik -el brazo político de la CONAIE- quebró la alianza y abandonó el gobierno. No obstante esta ruptura, se produjo un reflujo del movimiento indígena y una disminución del nivel de las movilizaciones y el conflicto político debido a diversos factores, entre ellos las tensiones cada vez mayores entre las diversas tendencias político-ideológicas dentro del movimiento indígena. Si bien la economía encontró cierta estabilidad, las dificultades comenzaron a provenir del frente político-partidario. Gutiérrez procuró establecer alianzas con los partidos políticos tradicionales e intervino inconstitucionalmente la Corte Suprema de Justicia para reemplazar a su directiva por una nueva afín al gobierno, que desactivara los juicios contra Bucaram, el ex presidente exiliado en Panamá. Estas maniobras políticas arbitrarias, así como el retorno efectivo de aquél al país, generaron una masiva ola de protestas y 
movilizaciones ciudadanas, localizadas sobre todo en la ciudad de Quito (Ramírez Gallegos, 2005), al calor del reclamo "Que se vayan todos", al igual que había ocurrido a fines de 2001 en Argentina. Las FFAA retiraron el apoyo al presidente Gutiérrez, a quien sucedió constitucionalmente Alfredo Palacio, lo que marcaría un giro en la orientación económica del Ecuador y prepararía el terreno para que Rafael Correa, ministro de Economía del nuevo gobierno, asumiera la presidencia en enero de 2007.

En Bolivia, por su parte, si bien todavía no tenía fuerzas suficientes para llegar al gobierno nacional, crecía progresivamente el "evismo". En 2002, el Movimiento al Socialismo (MAS) había proclamado a Morales como candidato a presidente para las elecciones de junio, y éste obtuvo el segundo lugar con el 20,94\% (8 senadores y 27 diputados). Morales contó mayoritariamente con el apoyo del occidente del país, como las zonas cocaleras del Chapare, los Yungas de La Paz, Cochabamba y Oruro. Además, había logrado interpelar a sectores de las clases medias urbanas. La importante elección que realizó el MAS lo fortaleció al interior del Congreso y contribuyó a su expansión nacional. Luego de la Guerra del Gas, el MAS tuvo la capacidad de posicionar los reclamos sociales vertidos los últimos dos años por distintos sectores populares, como el rechazo a la privatización de los servicios públicos y los recursos naturales estratégicos. En las elecciones municipales de 2004, el MAS fue el partido más votado: ganó 156 alcaldías, 462 concejales, y en el área rural de Cochabamba obtuvo el 52 \% de concejales (Rendón Corona, 2013).

El triunfo del Frente Amplio en Uruguay en 2004, y la llegada al gobierno de Tabaré Vázquez el 1 de marzo de 2005, consolidó el eje atlántico-caribeño y le dio mayor fortaleza a la influencia de lo nacional-popular en la región. De esta manera, en el interior del MERCOSUR ganaron terreno las fuerzas nacionales alineadas con el desarrollo de un proyecto de capitalismo productivo, regional y neodesarrollista, y, subordinadamente, también ganaron terreno las fuerzas que expresaban un contenido social-popular con una orientación más anclada en horizontes no capitalistas y una mayor radicalidad antiimperialista y latinoamericanista. Estas fuerzas sociales, más identificadas con las consignas programáticas de lo que sería el Socialismo del Siglo XXI, se vieron potenciadas por la constitución de la Alternativa Bolivariana para las Américas (ALBA) el 14 de diciembre de 2004, encabezada por Cuba y Venezuela. A partir de allí podemos establecer dos tendencias centrales en el interior del regionalismo autónomo y los nacionalismos populares: la nacional neodesarrollista (más predominante en el MERCOSUR) y lo popular-radical (más predominante en el ALBA y en el Socialismo del siglo XXI, que se instala en Venezuela a partir de 2006). Estas dos tendencias se vieron reflejadas en las trayectorias de acción y cambio político que los caracterizaron y que asumirán también los subsiguientes gobiernos postneoliberales (Ramírez Gallegos, 2010). La primera trayectoria alude a reformas graduales en el sistema político vigente, la combinación de estrategias de acumulación ortodoxas y heterodoxas, y el establecimiento de políticas dirigidas a expulsar a las corporaciones de las decisiones estatales. La segunda trayectoria de cambio procura convocar al poder originario ("el pueblo") para la participación en la redacción de una nueva constitución entendida más allá de su sentido procedimentalliberal. La demanda por una nueva constitución, que se había instalado públicamente "desde abajo", tuvo eco en los líderes políticos que motorizaron los procesos de cambio. Asimismo, esta trayectoria alude a una transformación de la comunidad política, para integrar a los históricamente excluidos y expulsar a los partidos tradicionales y corporaciones. En lo económico, esta trayectoria acude a medidas rupturistas con el modelo neoliberal, como nacionalizaciones ${ }^{5}$, expropiaciones y mayor participación del Estado en los ingresos.

\section{Momento 3 (noviembre de 2005 y 2011): avance estratégico del nacionalismo popular latinoamericano y la continentalidad suramericana}

El "No al ALCA" en la Cumbre de las Américas de Mar del Plata de noviembre de 2005 constituyó otra coyuntura crítica que dio inicio a un nuevo momento en la región. A partir de allí, cuando el rechazo 
marca un momento defensivo por parte del eje atlántico-caribeño frente al avance de los Estados Unidos y su plan continental, comienza una ofensiva estratégica del regionalismo autónomo en América Latina y el Caribe.

La cumbre del MERCOSUR durante el mes de junio de 2006 en la ciudad de Córdoba da cuenta de este cambio. Allí se inicia el proceso para la incorporación de Venezuela como miembro pleno del bloque (lo cual trabará el senado de Paraguay durante 6 años). Además, asiste Fidel Castro para consolidar la relación con el ALBA, alivianar el bloqueo de Estados Unidos a Cuba y apuntalar el eje atlántico-caribeño.

Desde ese entonces comienza a darse una serie de resultados electorales en distintos países de la región en donde triunfan fuerzas nacionales y populares que articulan organizaciones con base en distintas clases y grupos sociales subordinados, alineadas con la tendencia popular-radical. El primer resultado clave es el triunfo de Evo Morales el 18 de diciembre de 2005 (54\%) y su asunción en Bolivia el 22 de enero de 2006, que fortaleció al bloque popular emergente bajo la identidad del "evismo" -identidad emergente de bloque social de los oprimidos- e inició un proceso de transformación en Bolivia, que comenzó por la nacionalización de los hidrocarburos ${ }^{6}$. Esto último será un rasgo importante para observar y analizar los procesos posneoliberales: la apropiación por parte del Estado de la renta de los recursos naturales no renovables, así como el control de dicha explotación.

En Ecuador, Rafael Correa triunfa el 26 de noviembre de 2006 y asume el 15 de enero de 2007. Dejar atrás "la larga y triste noche neoliberal" y desmontar el poder de la "partidocracia" habían sido sus grandes ofertas de campaña. El discurso de Correa fue profundamente antineoliberal y bolivariano; construye como adversarios políticos a la elite económica, a los organismos internacionales de crédito y a la clase política ecuatoriana. Ello suma a otro país clave al eje bolivariano que se expresaría en el ALBA. Por otra parte, cierra el período de crisis política y empate "catastrófico" que se inicia a fines de los años noventa, cuando se pone de manifiesto la imposibilidad de la hegemonía neoliberal ${ }^{7}$.

El triunfo del obispo Fernando Lugo en Paraguay en agosto de 2008, en un frente con el Partido Liberal, completó finalmente el giro en todos los países del MERCOSUR. También expresó la presencia de un componente fundamental del giro nacional popular: los sectores de tendencias nacionales-populares de la Iglesia Católica. Este componente, que incluye distintas líneas de la Iglesia, estará presente en todas las articulaciones político-sociales que se levantan contra el neoliberalismo, aunque en el caso de Paraguay va a ser protagónico. Debemos destacar también en este sentido uno de los hechos centrales que simbolizaron el nuevo momento de la Iglesia Católica en la región, y que fue un momento fundamental del camino que desembocó en la elección del Papa Francisco en 2013: el documento de Aparecida (Brasil) de la V Conferencia General del Concejo Episcopal Latinoamericano y del Caribe. El mismo Papa Francisco fue uno de los redactores finales del documento, que expresa un llamado a la opción preferencial por los pobres y los excluidos, y la necesidad de formar una comunidad regional de naciones en América Latina y el Caribe ${ }^{8}$.

El proceso de avance geoestratégico se corporiza en la constitución de la Unión de Naciones Suramericanas (UNASUR) en mayo de 2008, conformada por los doce países de Suramérica. Para buena parte del pensamiento geopolítico regional con influencia en los gobiernos posneoliberales de la región, Suramérica es el territorio básico para el desarrollo de un "Estado continental", cuyo núcleo es el MERCOSUR, a partir de la alianza de Brasil y Argentina y la integración estratégica de la Cuenca del Plata (Methol Ferré, 2013). También los clásicos de la geopolítica del Brasil apuntan a Suramérica como el espacio fundamental de la proyección estratégica de dicho país (Travassos, 1978). Así lo destaca el propio Lula cuando se formalizó la UNASUR el 23 de mayo de 2008 en Brasilia: "América del Sur unida moverá el tablero de poder del mundo". Junto a la UNASUR se creó el Consejo Suramericano de Defensa (CSD), un Centro de Estudios Estratégicos de la Defensa del CSD, una escuela de formación para militares ${ }^{9}$, la construcción de un avión de entrenamiento suramericano ${ }^{10}$ y los primeros acuerdos de constitución del Banco del Sur. Además, UNASUR se erigió como un organismo regional que sustituyó de hecho a la OEA en asuntos de seguridad regional $^{11}$. 
La constitución de la UNASUR fue fundamental para resolver el conflicto autonomista en Bolivia, en el cual las prefecturas de la Media Luna "oriental" amenazaron con desintegrar el Estado boliviano presentándose en pie de guerra frente al gobierno del MAS y la nueva Constitución boliviana. Luego del contundente triunfo por parte de Evo Morales y de García Linera en el referéndum revocatorio de agosto de 2008 impulsado por la oposición, donde obtuvieron el $67 \%$ de los votos a favor de su continuidad, se profundizó una escalada de enfrentamientos entre las fuerzas del bloque popular emergente y las fuerzas conservadoras neoliberales que dominaban las prefecturas orientales y que, luego de desconocer el resultado, se llamaron a la desobediencia civil con el apoyo del embajador por los Estados Unidos Philip Goldberg. Dicha escalada de violencia por parte de la oposición al gobierno de Evo Morales derivó en la Masacre de Pando, donde murieron 13 campesinos y 2 funcionarios de Pando, producto de un accionar planificado para llevar a dicho plano el enfrentamiento entre las fuerzas en pugna. Este "punto de bifurcación" consolidó el nuevo estado de relación de fuerzas a favor del naciente bloque nacional popular. Pero esto no fue particular de Bolivia sino de toda la región, y la intervención de la UNASUR fue decisiva no sólo con respecto a la situación de Bolivia sino que el modo en que se resolvió dicha situación fue dirimente para la región, como antes lo había sido la insurrección popular que desarticuló el golpe en Venezuela. Y esto fue particularmente importante luego de la situación que transitó Argentina con el lockout agrario, en la cual se fortalecieron momentáneamente las fuerzas neoliberales (Varesi, 2014). Asimismo, el rol de UNASUR también será clave durante la insubordinación policial devenida en intento de golpe de Estado perpetrado en Ecuador el 30 de septiembre de 2010 por grupos de policías y de las fuerzas armadas asociados a segmentos de la clase política opositora al gobierno de Correa (Stoessel, 2013).

Por último, el 23 de febrero de 2010 se crea la Comunidad de Estados Latinoamericanos y Caribeños (CELAC), y queda definitivamente constituida en diciembre de 2011 en la cumbre de Caracas. Sobresale de dicho espacio la ausencia de Estados Unidos y Canadá, el paralelismo que se genera con la Organización de Estados Americanos (OEA) y la integración de Cuba - por fuera de la OEA y excluida de la Cumbre de las Américas-, que incluso tuvo la presidencia pro tempore y actuó de anfitrión de la segunda cumbre de la CELAC. La creación de la CELAC cristalizó el máximo punto de llegada del regionalismo autónomo y del giro nacional popular en la región.

\section{Momento 4 (abril de 2011 a octubre-diciembre de 2015): Estancamiento, crisis y fractura regional}

En abril de 2011, en Lima, se sientan las bases para la conformación de la Alianza del Pacífico (AP), por iniciativa del entonces presidente peruano Alan García Pérez: "Esta no es una integración romántica, una integración poética, es una integración realista ante el mundo y hacia el mundo", sostuvo en su fundación, destacando la perspectiva pragmática, que consiste en la aceptación de las fuerzas del mercado como garantes del orden social y los procesos de integración, y la aceptación del lugar asignado a la región en el Orden Mundial. Este cambio en la región se vislumbra en un nuevo contexto geopolítico global (Merino, 2014; Narodowski y Merino, 2015). En marzo de 2011 entramos en un nuevo momento de la crisis (transición histórica), con la guerra civil en Siria y luego en Libia, más la agudización de las tensiones en el mar de China (Merino, 2016). Como se observa en los distintos escenarios del enfrentamiento, este momento se caracteriza por la agudización de las tensiones entre los bloques de poder centrales ("Occidente") y los bloques de poder emergentes. China, Rusia e Irán, y el bloque MERCOSUR-ALBA sienten las presiones de esta nueva situación global, en la cual, a pesar de la creciente multipolaridad relativa, cambian las relaciones de poder. Las fuerzas centrales del orden mundial en crisis observan como un desafío las estrategias de distintos actores, que conforman un creciente multipolarismo relativo, y su pretensión por construir bloques para convertirse en nuevos polos de poder. 
Los llamados BRICS (Brasil, Rusia, India, China y Sudáfrica) y aliados, que unos años atrás eran territorios centrales de la expansión del capital transnacional y solución espacial de la crisis (y, por ello, posibles actores en una nueva institucionalidad global multilateral) -en la medida en que desarrollan mayores niveles de autonomía relativa, construyen bloques de poder y aprovechan la crisis y contradicciones del "viejo centro" mundial para impulsar sus propios proyectos políticos estratégicos- se convierten en obstáculos para las fuerzas "occidentales" y para el capitalismo global. Este enfrentamiento se agudiza en 2014 con el estallido de la guerra civil en Ucrania, la escalada del conflicto sirio y el despliegue de tropas rusas en dichos territorios, la construcción de una nueva institucionalidad financiera mundial por parte de los BRICS acordada en la cumbre de Fortaleza en Brasil en julio 2014, y la incorporación de nuevos miembros a la Organización para la Cooperación de Shanghái, liderada por China y Rusia, que constituye una poderosa alianza de seguridad euroasiática por fuera de la OTAN y de las potencias occidentales más Japón, entre otras cuestiones.

En este contexto se constituye la $\mathrm{AP}$, que rescata los pilares del regionalismo abierto y está a favor de una mayor cercanía geopolítica con los Estados Unidos en particular y con "Occidente" en general. La AP está centrada, como tal, en la libertad de comercio, la atracción de las inversiones extranjeras, los acuerdos de libre comercio, la explotación de las ventajas comparativas (fundamentalmente la explotación de recursos naturales) y el desarrollo puesto en relación a la integración en el capitalismo global del siglo XXI (Merino, 2017). Conformada en un principio por Chile, Colombia, Perú y México -y con Costa Rica, Panamá y Guatemala en proceso de incorporación-, la AP forma parte como eslabón regional de un esquema de integración más amplio del capitalismo global, denominado Acuerdo Estratégico Trans-Pacífico de Asociación Económica (conocido como TPP, por sus siglas en inglés), originalmente establecido por Chile, Brunei, Singapur y Nueva Zelanda en 2005, pero del que pasaron a formar parte y firmar la iniciativa, en 2016, Australia, Canadá, Japón, Malasia, México, Perú, Estados Unidos y Vietnam. El TPP, prioritario en la agenda internacional del gobierno de Obama en los Estados Unidos, constituía una amenaza para China ya que implicaba una disputa en su zona fundamental de influencia, el Asia Pacífico. El control del Pacífico aparece como objetivo estratégico para Estados Unidos y aliados, y las fuerzas fundamentales del capitalismo global. Como afirmaba Hillary Clinton, "el futuro de la política mundial se decidirá en Asia y en el Pacífico, no en Afganistán o Irak, y Estados Unidos deberá estar justo en el centro de la acción” (Clinton, 2011). En este sentido, la AP constituía una política de integración estratégica en el marco de la TPP, e implicaba un cerco y una política de "contención" tanto para la Organización para la Cooperación de Shanghai (encabezada por China y Rusia), que compite con la OTAN, como también para el bloque ALBA-MERCOSUR, hoy en retroceso y desarticulación. La diferencia de la AP con el regionalismo autónomo se señala claramente en un dossier sobre el tema, publicado por el Financial Times (2/4/2014), en el que se afirma que este nuevo bloque "abre las puertas para los negocios en la región”, y se resalta positivamente que, a diferencia del MERCOSUR, ésta es una alianza económica y no política, algo que también señalan los líderes políticos de la AP. Allí, Barbara Kotschwar afirma que "si el Mercosur representa el socialismo del siglo XXI, la Alianza Pacífico representa el capitalismo del siglo XXI" ${ }^{12}$. En este sentido, se debe señalar que todos los integrantes de la AP poseen tratados de libre comercio con los Estados Unidos, a los cuales se opusieron estos últimos años los países que integran el MERCOSUR y el ALBA ${ }^{13}$.

A este nuevo contexto geopolítico se le suma la caída relativa en los precios de los commodities a nivel mundial, luego del pico de 2011, lo cual golpea a los ingresos por exportaciones de los países de la región. Esto agudizó los problemas de falta de divisas en economías que habían tenido un importante aumento del consumo debido a los incrementos de salarios y a la transferencia de recursos hacia las clases populares mediante políticas públicas. Así se volvió a producir el típico cuello de botella de las economías latinoamericanas desequilibradas, con competitividad en su sector primario, debido a las ventajas comparativas estáticas que posee, y su baja competitividad en el sector industrial y de servicios complejos (en el caso de que por lo menos tuvieran algún desarrollo propio esos sectores) ${ }^{14}$. Esta situación coadyuvó en las crisis de las articulaciones nacionales populares de algunos países, como Argentina, Brasil y Ecuador, 
ya que se desató el dilema de la "frazada corta". Mientras la economía crecía, todos los grupos sociales y clases podían encontrar satisfacción de sus demandas e intereses construidos, es decir, la frazada alcanzaba a cobijar a muchos. El nacionalismo popular podía ser aceptado por casi todos o soportado por aquellos que tenían diferencias políticas, ideológicas y estratégicas, pero que no lograban rearticular una oposición neoliberal contundente a los gobiernos "populistas". Cuando la frazada queda corta, se agudizan las luchas por la distribución de riquezas, incluso (y especialmente) entre los grupos que articulan y pretenden expresar los gobiernos nacionales y populares, lo que debilita dicha articulación. En el núcleo de este problema está la cuestión de la dependencia y el accionar oscilante de la burguesía local interna ${ }^{15}$.

Si bien el golpe en Honduras en 2009 fue un anticipo de contraofensiva neoliberal unipolar, ya que luego de varios intentos lograba triunfar un golpe de dicha naturaleza en la región, fue la destitución de Fernando Lugo en junio de 2012, a través de un golpe parlamentario, el primer triunfo importante de la contraofensiva neoliberal unipolar en Suramérica. Podemos considerar dicha destitución como una coyuntura crítica, que no sólo expresó a las claras dicha contraofensiva, sino que en lo particular marcó el inicio del repliegue de las fuerzas nacionales-populares en los gobiernos. En Paraguay, en el corazón del continente y del MERCOSUR, se impuso un gobierno conservador, afín a la política del Comando Sur de los Estados Unidos y favorable a la construcción de dos bases militares para la potencia imperial que venía desde hacía 13 años perdiendo influencia en la región. Ello coincidió, como se mencionó anteriormente, con el lanzamiento de la AP, que fracturó la UNASUR, permitió la resurrección del regionalismo abierto y la retomada de la influencia dominante de Washington en los asuntos regionales.

\section{Momento 5 (octubre-diciembre de 2015 a diciembre de 2018): La ofensiva del proyecto financiero neoliberal unipolar y reflujo de las fuerzas nacionales, populares y latinoamericanas.}

El arribo al poder gubernamental, ya sea a través de "golpes parlamentarios" (Michel Temer en Brasil) o del voto popular de fuerzas políticas que se reivindican de (centro) derecha reconfiguró el mapa político a partir de octubre de 2015. Si bien la victoria electoral de Horacio Cartes en Paraguay (2013) era un indicio del nuevo momento regional, como abordamos en el momento anterior, el triunfo de Mauricio Macri en Argentina en octubre de 2015 y el inicio del juicio político ilegítimo a Dilma Rousseff en diciembre del mismo año modificó definitivamente el escenario regional, lo cual se completará con la destitución de la presidenta brasilera en agosto de $2016^{16}$. Ambos acontecimientos forman parte de una coyuntura crítica que consideramos aún en curso. A ello le siguió el triunfo electoral de Pedro Pablo Kuczynski en Perú (2016) -renunció al cargo el 21 de marzo de 2018 a raíz de diversas acusaciones y denuncias de corrupción-, de Lenin Moreno en Ecuador (2017) ${ }^{17}$ y de Sebastián Piñera en Chile (2018) ${ }^{18}$. Consideramos que la victoria electoral de la coalición "Cambiemos" en Argentina (Macri ganó en segunda vuelta en noviembre de 2015) constituyó el hito a nivel regional que en términos institucionales selló un "giro hacia la derecha" y en términos estratégicos un gran avance para el proyecto financiero neoliberal. Asimismo, la victoria de la MUD (Mesa de la Unidad Democrática, oposición al gobierno de Maduro, sucesor de Chávez) en las elecciones parlamentarias en Venezuela (en diciembre 2015) aportó más evidencia del reflujo de las fuerzas gobernantes progresistas y al debilitamiento de las fuerzas populares en la calle. Mientras el debate acerca de los alcances que tuvo la consolidación de las fuerzas nacionales y populares y el continentalismo sudamericano (el momento 3) no había terminado de zanjarse, el nuevo giro que atraviesa a la región reconfiguró la discusión.

Dos grandes tesis organizaron la explicación de este momento. La primera, sostenida en la idea de la "restauración conservadora", postula que las derechas y elites latinoamericanas recobraron la iniciativa para motorizar una vuelta al neoliberalismo y restablecer un Estado mínimo, tal como lo experimentamos durante 
los años noventa (Katz, 2016). La otra tesis, que discute con aquélla, declara que estamos presenciando la emergencia de "nuevas derechas" en el gobierno, que ya no defienden discursivamente las políticas de ajuste estructural sino que se muestran más sensibles con la "cuestión social" y proclives a admitir la necesidad de la intervención estatal en distintos ámbitos de la sociedad (Giordano, 2014; Vommaro, 2017). En definitiva, ambas posiciones dieron cuenta de que la región comenzó a presenciar un cambio político - "fin de ciclo" para algunos (Svampa, 2017), "repliegue progresista temporal”, para otros (García Linera, 2017)- que ya evidencia ciertas mutaciones respecto al ciclo anterior.

En medio de este debate nos interrogamos acerca de este momento, y proponemos una hipótesis de trabajo para profundizar en futuras investigaciones: asistimos a un fin de ciclo político, más no a un fin de ciclo histórico, en la medida en que la disputa abierta en torno a "lo postneoliberal" durante el siglo XXI aún expresa un campo de lucha en plena ebullición. Los procesos políticos que giraron nuevamente hacia un proyecto neoliberal enfrentan importantes dificultades para establecer alternativas sostenibles en el tiempo. Estas dificultades se evidencian claramente a través de los distintos frentes de resistencia en boga, desde sectores productivos, sindicales, estudiantiles, movimientos sociales ligados a la economía popular y al medio ambiente, etc. Si bien es cierto que estos procesos están conduciendo a un debilitamiento del campo popular progresista (las drásticas medidas económico-sociales actuaron como un disciplinador social, generando rápidamente un aumento en los indicadores de desempleo y pobreza, y el acuerdo reciente entre la Argentina y el FMI empeorará dichos indicadores), las fuerzas sociales opuestas a los proyectos neoliberales de los gobiernos vigentes aún demuestran una fuerte capacidad de resistencia.

Respecto a los países que no lograron dar un viraje anti o postneoliberal durante la primera década del siglo, como Colombia y México, en el último año presenciamos allí el fortalecimiento de fuerzas políticas progresistas. Luego de la ajustada victoria del "NO" en el plebiscito por los acuerdos de paz llevado adelante en Colombia en octubre de 2016 (el rechazo a los acuerdos de paz fue promovido activamente por el expresidente de derecha Álvaro Uribe), el país andino, no obstante, experimentó el robustecimiento de fuerzas que se reconocen como de izquierda ${ }^{19}$. Las elecciones presidenciales de 2018 dieron la victoria a Iván Duque (del partido uribista Centro Democrático) frente a Gustavo Petro, exalcalde de Bogotá y líder del Movimiento Colombia Humana de centro-izquierda. Sin embargo, Petro obtuvo más de ocho millones de votos, lo cual es inédito en la historia colombiana. Por otro lado, la reciente victoria del Movimiento Regeneración Nacional (MORENA) liderado por Andrés Manuel López Obrador en las elecciones del 1 de julio en México constituye un acontecimiento histórico, al posibilitar que llegue a la presidencia una fuerza de izquierda. Además, MORENA cuenta con mayoría parlamentaria en la Cámara de Diputados y obtuvo la victoria en cinco gobernaciones, incluida la capital. Aún no está claro si dicho acontecimiento podría ser considerado una coyuntura crítica que abriera opciones de cambio, en la medida en que aún es prematuro pronunciarnos sobre el devenir del proceso mexicano y sus posibilidades de quebrar con el modelo neoliberal conducido por el poderoso Partido Revolucionario Institucional (PRI), que gobernó el país durante siete décadas de forma consecutiva.

Los países que sí fueron parte del mentado "giro a la izquierda" durante el siglo XXI, y cuyas fuerzas aún permanecen en el poder gubernamental, como Bolivia y Venezuela, atraviesan cierto debilitamiento asociado a varios factores. En el caso de Bolivia, Evo Morales perdió un referéndum en 2016, convocado por la propia fuerza gobernante, para reformar la Constitución de forma tal de poder postularse a una tercera elección presidencial. Fue su primera derrota electoral en diez años de gobierno. Dicho resultado expresó no sólo cierto desgaste político, pese al éxito económico del modelo boliviano. Bolivia es uno de los países latinoamericanos con mejores indicadores económicos (como crecimiento, cuentas fiscales y redistribución del ingreso) gracias a una combinación entre políticas ortodoxas y un fuerte intervencionismo estatal (Stefanoni, 2016). También dio cuenta de la pérdida de apoyo social de lo que inicialmente fueron las bases electorales del MAS, el movimiento político liderado por Evo Morales, así como de la pérdida de iniciativa política: la campaña oficialista de cara al referéndum se apoyó más en consignas "conservacionistas" 
del orden que en propuestas capaces de reconducir el proyecto político (Stefanoni, 2016). En Venezuela, la pérdida de apoyo político-electoral se suma a la delicada situación económico-institucional que atraviesa, especialmente desde el año 2013 con la muerte de Chávez.

En el caso de Argentina, Brasil y Ecuador donde se evidencia a las claras un viraje hacia el PNF y un fin de ciclo político, los poderes gubernamentales atraviesan serias dificultades tanto respecto a sus modelos económicos, legitimidad política e inserción regional-transnacional. En el caso de Argentina, Mauricio Macri, pese a aparentemente haber ratificado su legitimidad en las elecciones legislativas de 2017, enfrenta una economía en recesión, fuga de capitales y endeudamiento. En Brasil, las perspectivas políticas y económicas para la reciente fuerza gobernante no son mejores. Ya con el ascenso de Michel Temer se puso en marcha una agenda para desarticular el proyecto de regionalismo autónomo continental (aunque fuera débil), asumir un regionalismo abierto liberal y desvincular en términos geopolíticos a Brasil de los BRICS (especialmente de China y Rusia). Además, se vuele a reimplantar un programa neoliberal comandado por el capital financiero, que rápidamente se cristalizó, entre otras cosas, en una legislación laboral de flexibilización regresiva para los trabajadores (que motivó una huelga general luego de más de 20 años) y un congelamiento del gasto público por ley por 20 años. La agenda neoliberal, impulsada por el poder financiero, los grandes terratenientes, el monopolio mediático comandado por la Red Globo y el sector profundamente conservador del poder judicial, está causando estragos a nivel social y debilitando todas las estructuras del poder nacional de Brasil, mientras los escándalos de corrupción enlodan a las principales figuras del gobierno de Temer (comenzando por éste, quien fuera finalmente encarcelado en marzo 2019), así como a los referentes de los otros partidos políticos tradicionales. La victoria electoral del ex militar Jair Bolsonaro - dada la prohibición del Tribunal Superior Electoral para que Lula pudiera presentarse como candidato - y su asunción en enero 2019 en enero constituye un acontecimiento "dramático", no sólo para el país conosureño sino también para la región. Bolsonaro asume la presidencia luego de ganar en balotaje al candidato del PT, Fernando Haddad- con un discurso neofascista (xenófobo, homófobo y de extrema derecha) (Costa, 2018), e inaugura en la región lo que algunos autores ya habían anunciado como el "momento neofascista" del neoliberalismo, encabezado por la victoria de Donald Trump en Estados Unidos (enero 2017) (Fassin, 2018).

El caso de Ecuador es reciente para analizar, pero algunas cifras ya arrojan resultados ampliamente negativos para las grandes mayorías que apoyaron electoralmente a este gobierno en la presunción de que Moreno sería un continuador del proyecto de la Revolución Ciudadana liderada por R. Correa. En tan sólo quince meses de gobierno, la pobreza extrema aumentó considerablemente: del $59 \%$ registrado a principios de 2017 se pasó a un 63,3 para fines de ese año (cifras extraídas del Instituto Nacional de Estadística y Censos de Ecuador). Asimismo, la redistribución de los factores de poder hacia las elites y grupos concentrados de la economía a través de determinadas medidas así lo demuestran: otorgamiento del dinero electrónico a la banca privada; exención de impuestos; condonación de deuda a los grandes capitales; aprobación de la Ley Orgánica de Fomento Productivo, Atracción de Inversiones, Generación de Empleo, Estabilidad y Equilibrio Fiscal ${ }^{20}$; el debate abierto desde el Poder Ejecutivo para derogar la ley de comunicación aprobada en 2012, que prohibía los monopolios mediáticos; una composición tecnocrática del gabinete ministerial (empresarios, banqueros y asesores de think tanks, y ONG liberales en los altos cargos ejecutivos). Todas estas políticas y decisiones son similares a la matriz implementada desde diciembre 2015 en Argentina por el gobierno de Cambiemos. El perfil empresarial de la clase gobernante -o su cercanía con las elites económicas(Canelo y Castellani, 2017) y la implementación de medidas de corte neoliberal -como flexibilización laboral, reducción del gasto público, liberalización económica, financiarización de la economía- dan cuenta de ello.

Uno de los cambios centrales para analizar la situación regional fue el triunfo de Donald Trump en Estados Unidos, que produce un cambio de las correlaciones de fuerzas a favor de lo que definimos como fuerzas americanistas y nacionalistas (con solapamientos y contradicciones) en detrimento de las fuerzas globalistas. La estrategia nacionalista-americanista, resumida en el eslogan "Estados Unidos primero", es el producto 
de un conjunto de actores que ven como una amenaza la pérdida de la capacidad de decisión nacionalestatal, y la pérdida de la primacía mundial a partir de la subordinación a instituciones "globales", acuerdos y tratados multilaterales, el respeto por las alianzas tradicionales y la emergencia de potencias desafiantes (Merino, 2018b). El nacionalismo-americanismo de Trump busca "recuperar" la hegemonía estadounidense en el sistema mundial como Estado-nación y fortalecer unilateralmente el polo angloamericano con vértice en Washington para, desde ahí, librar las luchas contra los polos de poder desafiantes y disciplinar a los aliados. Para ello, resulta fundamental recuperar la hegemonía en el continente americano, desde el cual proyectarse a nivel mundial. Y en tal sentido se profundizan las políticas de seguridad hemisférica, enmarcadas en la doctrina Monroe, que exacerban el intervencionismo en la región frente a cualquier alternativa que ose desafiar los intereses de Washington. El gobierno retorna a la política exterior del "eje del mal", definido por Bush (en donde se incluía a Irán, Irak, Corea del Norte, Libia, Siria y Cuba, a los que luego se agregaron Bielorrusia, Birmania y Zimbabwe) como territorios de la lucha político-estratégica por el dominio del orden mundial. El desarrollo de posibles guerras en dichos territorios secundarios tiene como objetivo conquistar posiciones claves y/o impedir el avance de potencias rivales, a la vez que alimentar la economía doméstica de los Estados Unidos y hacer uso del monopolio del dólar para su financiamiento. En este sentido, del discurso de Trump en la ONU contra Cuba y Venezuela (incorporada al eje del mal, junto con Nicaragua) en nombre de la lucha contra el "socialismo" queda claro que hay una decisión de profundizar el plano ideológico de la lucha y exagerar el tono mesiánico propio de la tradición imperialista estadounidense Estados Unidos como fuerza del bien y como pueblo de Dios según el “destino manifiesto"-. La intención de intervenir militarmente en Venezuela para desplazar al gobierno de Maduro, junto con las sanciones y las enromes presiones para producir un golpe de Estado (admitido e impulsado públicamente por la administración Trump), muestra con claridad la nueva geoestrategia regional. La reedición exacerbada de la doctrina Monroe, que se amplía a otras dimensiones del poder más allá del militar, es confirmada por jefe del Comando Sur de Estados Unidos, el almirante Kurt Tidd, cuando señala insistentemente que las inversiones de China y la influencia de Pekín en América Latina (como también de Rusia y de Irán) constituyen una amenaza para la seguridad nacional ${ }^{21}$. Y la política de Washington puede tornarse cada vez más belicista en la región a medida que las fuerzas del viejo imperialismo americano sigan retrasándose y debilitándose en el escenario internacional.

La política de la administración Trump puso en crisis la AP al desvincular a Estados Unidos del TPP, lo que generó una profunda tensión con las propias fuerzas neoliberales de la región. La política de "palos sin zanahorias" o la puesta en crisis por parte de Washington de algunos de los preceptos fundamentales de la visión neoliberal, como por ejemplo la cuestión comercial, constituyen un problema para el giro político a la "derecha" que analizamos en esta última etapa. La firma del Tratado Integral y Progresivo de Asociación Transpacífico (CPTPP, por sus siglas en inglés) puede ser vista como una respuesta político estratégica al gobierno de Trump por parte de fuerzas globalistas y grupos de poder locales de orientación neoliberal, lo que marca una tensión a la estrategia nacionalista-americanista. Por otro lado, los movimientos políticos regionales en las elecciones de México, Colombia, Venezuela estarían indicando serias dificultades para la reposición de la hegemonía estadounidense en la región, pero ello, a su vez, se responde desde Washington con mayores escaladas, en especial con Venezuela, Cuba y Nicaragua. Por su parte, Brasil, con la elección de Bolsonaro, muestra un alineamiento total y la posibilidad de protagonizar una política subimperialista, al constituirse en polea de transmisión de los intereses dominantes de Washington en la región. Sin embargo, el vicepresidente Hamilton Mourão, máximo representante de las fuerzas armadas en el gabinete presidencial, frenó muchas de las decisiones que Bolsonaro pretendía tomar en su política de alineamiento total con Estados Unidos, como la de acompañar una aventura militar en Venezuela ${ }^{22}$. 


\section{REFLEXIONES FINALES}

En este trabajo procuramos proponer un modo de periodizar las últimas dos décadas en Suramérica en relación al giro nacional-popular implementado en buena parte de los países latinoamericanos desde 1999 con la asunción de Hugo Chávez en Venezuela. La identificación de cinco momentos a través de los cuales se produjo la transición histórica, desde principios del siglo hasta entonces, se realizó a partir de establecer de forma analítico-empírica coyunturas críticas. Esto se realizó a partir del cruce de los aportes del "análisis de fuerzas", con un enfoque geopolítico estratégico y elementos de economía política. Estos momentos dan cuenta de la conformación de bloques de poder político-económico en función de los proyectos neoliberalesfinancieros, y de los proyectos postneoliberales y antineoliberales en disputa.

Consideramos que esta propuesta puede contribuir a echar luces sobre el actual momento que atraviesa la región latinoamericana, el quinto momento identificado. Creemos que la tesis instalada, académica y políticamente, del "fin de ciclo político" asociado al actual ocaso de las fuerzas progresistas y al resurgimiento de "nuevas derechas" en América Latina oscurece más de lo que ilumina respecto a: a) los alcances y límites de la embestida del proyecto financiero neoliberal; b) las condiciones de posibilidad para que las fuerzas nacionales-populares hoy en repliegue traduzcan sus posiciones de resistencia en propuestas superadoras respecto a los límites de los proyectos postneoliberales tal como los experimentamos durante 2005-2015; c) la conformación de bloques regionales geoestratégicos capaces de hacer frente al (regreso del) unipolarismo del bloque financiero neoliberal; d) la fisura en Estados Unidos entre nacionalistasamericanistas y globalistas, el cambio de geoestrategia y las consecuencias para la región. A partir del estudio y cruce de estas dimensiones consideramos que pueden superarse las dificultades de una comprensión de los procesos políticos contemporáneos basados en el clivaje izquierda-derecha, en la medida en que existen múltiples pliegues en los bloques de poder y actores políticos que los conforman. Actores que se reconocen en una matriz progresista y de "izquierda" pueden no oponerse a mecanismos de integración regional que generan dependencia -como los TLC y el ALCA- y a la extranjerización de las economías, mientras que actores que no cuestionan aspectos estructurales del capitalismo neoliberal dependiente pueden centrarse en agendas ligadas a la ampliación de derechos civiles, como la legalización del aborto y del matrimonio igualitario. Ello complejiza la mirada y nos brinda una mayor riqueza en el análisis sobre las relaciones de fuerza/poder y la transición histórica-espacial en América Latina.

\section{REFERENCIAS}

Alves Teixeira, R. y Desiderá Neto, A. (2012). Perspectivas para la Integración de América Latina. Brasilia: IPEA. Arrighi, G. (2007). Adam Smith en Pekin. Origenes y fundamentos del siglo XXI. Madrid: Akal.

Basualdo, E. (coord) (2015). Deuda externa, fuga de capitales y restricción externa. Desde la última dictadura hasta la actualidad, Documento de Trabajo $N^{\circ} 68$, CEFIDAR. Recuperado de http://www.iade.org.ar/system/files/d t68.pdf

Canelo, P., y Castellani, A. (2017). Puerta giratoria, conflictos de interés y captura de la decisión estatal en el gobierno de Macri. El caso del Ministerio de Energía y Minería de la Nación. Informe de Investigación $N^{o} 2$. Buenos Aires: UNSAM -IADE.

Capoccia, G., y Kelemen, D. (2011). The Study of Critical Junctures: Theory, Narrative, and Counterfactuals in Historical Institutionalism. World Politics, pp. 341-360.

Clinton, H. (2011). America's Pacific Century. Foreign Policy. Recuperado de https://foreignpolicy.com/2011/10/ 11/americas-pacific-century/

Collier, R., y Collier, D. (1991). Shaping the Political Arena: Critical Junctures, the Labor Movement and Regime Dynamics in Latin America. Princeton: Princeton University Press. 
Costa, B. (2018). Quién es quién en el ejército de Jair Messias Bolsonaro. Nueva Sociedad, edición digital, http://nus o.org/articulo/quien-es-quien-en-ejercito-de-jair-messias-bolsonaro/.

Da Silva Guevara, G. (2018). Brasil y sus vecinos, estrategias de Smart Power (2003-2014). Bogotá: Universidad Externado de Colombia.

Diamand, M. (1983). Elpéndulo argentino: ¿hasta cuándo? Buenos Aires: Centro de Estudios de la Realidad Económica y Social.

Dussel, E. (2009). Politica para la liberación, Tomo II. Madrid: Editorial Trotta.

Fassin, E. (2018). El momento neofascista del neoliberalismo. Rebelión, de julio de 2018. Disponible en: http://www .rebelion.org/noticia.php?id=243584

García Linera, A. (2006). El evismo: lo nacional-popular en acción. OSAL, Año VI, 19, 25-32.

García Linera, A. (2009). El Estado en transición. Bloque de poder y punto de bifurcación. En P. Stefanoni (comp.), La potencia plebeya: acción colectiva e identidades indigenas, obreras y populares en Bolivia, pp. 501-525. Bogotá: Siglo del Hombre Editores y Clacso.

García Linera, A. (2017). ¿Fin de ciclo progresista o proceso por oleadas revolucionarias? Portal digital Pulso de los pueblos. Recuperado de http://pulsointernacional.com/fin-de-ciclo-progresista-o-proceso-por-oleadas-revoluci onarias-por-alvaro-garcia-linera/

Giordano, V. (2014). ¿Qué hay de nuevo en las «nuevas derechas?. Nueva Sociedad, 254, 46-56.

Harvey, D. (2003). El nuevo imperialismo. Madrid: Akal.

Jessop, B. (2017). El Estado, pasado, presente y futuro. Madrid: Los libros de la catarata.

Kan, J. (2015). La integración desde arriba. Los empresarios argentinos frente al MERCOSUR y al ALCA. Buenos Aires: CICCUS.

Katz, C., (2015). ¿Qué es el neodesarrollismo? Una visión crítica. Argentina y Brasil. Serv. Soc. Soc., 122, 224-249.

Katz, C. (2016). El viraje de Sudamérica. Pensamiento al margen. Revista digital, 4, 53-78.

Merino, G. E. (2011). Globalismo financiero, territorialidad, progresismo y proyectos en pugna. Revista Geograficando, 7, ISSN 1850-1885, 107-134.

Merino, G. E. (2014). Lucha entre polos de poder por la configuración del orden mundial. El escenario actual. Estudios Estratégicos, 1., 8-29.

Merino, G. E. (2015). El Grupo Productivo y el cambio de "modelo". Luchas por la conducción del estado en Argentina entre 1999 y 2003. Buenos Aires: Editorial Universitaria UNAM, CEFIPES, CEPES.

Merino, G. E. (2016). Tensiones mundiales, multipolaridad relativa y bloques de poder en una nueva fase de la crisis del orden mundial. Perspectivas de América Latina. Geopolitica(s): revista de estudios sobre espacio y poder, 2(7), 201-225. https://revistas.ucm.es/index.php/GEOP/article/view/51951

Merino, G. E. (2017). Proyectos estratégicos e integración regional en América Latina. El surgimiento de la Alianza del Pacífico, el fortalecimiento del regionalismo abierto y el retroceso del regionalismo autónomo. Relaciones Internacionales, 26(52), 17-37.

Merino, G. E. (2018a). Los tratados comerciales y las luchas globales en la era Trump. Realidad Económica, 313, 9-40.

Merino, G. E. (2018b). Del apogeo lulista a la destitución de Dilma: el devenir nacional popular neodesarrollista en Brasil. Latinoamérica, 66, 223-259.

Methol Ferré, A. (2013). Los Estados continentales y el Mercosur. Montevideo: Ed. HUM.

Narodowski, P., y Merino, G. E. (2015). La agudización de las tensiones globales. Análisis de la crisis del orden unipolar y los conflictos geoestratégicos desde una perspectiva centro-periferia. Estudios Socioterritoriales, 18, 81-99.

Pinedo, J. (2009). Los sentidos de la manifestación. Prácticas, relatos e imágenes en torno de la "Masacre del 26 de Junio en Avellaneda". Cuestiones de Sociología, pp. 79-99. https://www.cuestionessociologia.fahce.unlp.edu.ar/ article/view/CSn5-6a04/5199

Ramírez Gallegos, F. (2005). La insurrección de abril no fue sólo una fiesta. Quito: Taller El Colectivo, Abya-Yala, Ciudad, Terranova. 
Ramírez Gallegos, F. (2018). El 4 de febrero y la descorreización de Ecuador. Nueva Sociedad, s/p.

Rendón Corona, A. (2013). Bolivia. La revolución democrática y cultural. 2000-2011. México: Universidad Autónoma Metropolitana.

Stefanoni, P. (2016). El nuevo escenario político boliviano ¿Traspié electoral o fin de un ciclo? Nueva Sociedad, 262, $4-14$.

Stoessel, S. (2013). Políticas y conflicto político durante el post-neoliberalismo: el caso del “30-S” en Ecuador. Revista Perspectivas de Politicas Públicas, 141-170.

Stoessel, S. (2014). El giro a la izquierda en la América Latina del siglo XXI. Revisitando los debates académicos. Polis, 39. http://polis.revues.org/10453

Stoessel, S. (2017). Estado y representación política durante el ciclo postneoliberal: el vínculo entre poder gubernamental y transportistas en Argentina, Bolivia y Ecuador (Tesis de doctorado). La Plata: Universidad Nacional de La Plata.

Svampa, M. (2017). Del cambio de época al fin de ciclo. Buenos Aires: Edhasa.

Travassos, M. (1978). Proyección continental del Brasil. México: El Cid Editor.

Thwaites Rey, M. (2009). Después de la globalización neoliberal: ¿Qué Estado en América Latina? Revista OSAL, 2, 19-43.

Varesi, G. A\#. (2014). El "conflicto del campo" de 2008 en Argentina: Hegemonía, acumulación y territorio. Geograficando, 10(2), pp. 9-28.

Vommaro, G. (2017). La larga marcha de Cambiemos. La construcción silenciosa de un proyecto de poder. Buenos Aires: Siglo Veintiuno Editores.

\section{Notas}

1 García Linera (2006) ha caracterizado al "evismo" como un nuevo "actor" colectivo -aunque liderado por un referente, Evo Morales-, y una novedosa praxis política cuyos orígenes se remontan a fines de los años ochenta, a partir del establecimiento de una estrategia de poder fundada en las organizaciones y movimientos sociales.

2 https://www.clarin.com/ediciones-anteriores/duhalde-dijo-trato-golpe-chavez_0_BJrzRBHx0tx.html Última consulta: 15 de abril 2019.

3 De acuerdo a lo definido en Merino (2017), el regionalismo autónomo cuestiona el papel de periferia en el orden mundial e intenta establecer estrategias de desarrollo endógeno para colocar a la región como polo de poder en un escenario multipolar, frente al regionalismo abierto/liberal, que no cuestiona el lugar de periferia y el papel en la división internacional del trabajo, busca estrategias de adaptación al capitalismo mundial, plantea una alianza estratégica con los Estados Unidos, y, en términos más amplios, con "Occidente", y está centrado en la integración de las cadenas globales de valor dominadas por el capital transnacional. Desde otra conceptualización, aunque con un corte parecido, Alves Teixeira y Desiderá Neto (2012) consideran que la nueva ola de integración regional en el presente siglo recupera las viejas ideas desarrollistas "cepalinas" de los años sesenta, en oposición a un regionalismo liberal y al revisionismo "cepalino" de los años noventa, expresado en el concepto de regionalismo abierto.

4 Ver informe del Instituto de Relaciones Internacionales: http://www.iri.edu.ar/revistas/revista_dvd/revistas/R25/ri\%2025\% 20doc\%20MERCOSUR.pdf.ltima consulta: 3 octubre, 2018

5 Desde 2006, Evo Morales nacionalizará todos los $1^{\circ}$ de mayo de forma consecutiva diferentes empresas como expresión de la recuperación de la soberanía nacional. Por ejemplo, el 1 de mayo de 2009 Morales nacionalizó cuatro empresas eléctricas: Corani, participada en un 50 \% por Ecoenergy International, subsidiaria de la francesa GDF Suez; Guaracachi, cuyo principal accionista era la británica Rurelec PLC; Valle Hermoso, cuyo 50\% del capital estaba en manos de The Bolivian Generating Group de la Panamerican de Bolivia, y la cooperativa distribuidora Empresa de Luis y Ferza Eléctrica de Cochabamba. El 1 de mayo de 2012 hará lo propio con las acciones de Red Eléctrica Española (REEE). https://www.paginasiete.bo/nacional/2016/5/2/evo-boliviamayo-sinonimo-nacionalizacion-95146.html

6 Como parte de este proceso, también podemos mencionar que Daniel Ortega, líder del histórico Frente Sandinista de Liberación Nacional, asume la presidencia de Nicaragua el 10 de enero de 2007, luego de triunfar en las elecciones del 5 de noviembre de 2006. 
7 http://www.vidanuevadigital.com/wp-content/uploads/2013/04/Documento_Conclusivo_Aparecida.pdf. Última consulta: 27 de agosto, 2018.

8 http://unasursg.org/es/escuela-suramericana-defensa

9 https://www.infodefensa.com/latam/2015/05/02/noticia-definen-marco-creacion-empresa-construira-avion-entrenamien to-regional-unasur.html

$10 \mathrm{La}$ amenaza que significa UNASUR es señalada en documentos oficiales de los Estados Unidos. Este tema se desarrolla en Merino (2017)

11 Recuperado de: https://www.ft.com/content/32299f7c-aec2-11e3-a088-00144feab7de. Última consulta: 3 de octubre, 2018

12 Sin embargo, luego del triunfo de Donald Trump y con él de las fuerzas nacionalistas-americanistas en Estados Unidos, Washington se retira del TPP, dejando sin norte claro a la AP (lo que intenta subsanarse con el lanzamiento de un acuerdo transpacífico sin Estados Unidos) y modificando profundamente el escenario regional (Merino, 2018a).

13 Esta discusión es muy extensa y la referencia a autores sería enorme. Podemos señalar el clásico de Diamand (1983), o las discusiones que aparecen en Katz (2015) y en Basualdo (2015) para las experiencias de los últimos años de Argentina y Brasil.

14 Este problema se ve con mucha claridad en Brasil y lo trabajamos en parte en Merino (2018)

15 El golpe institucional para la destitución de Rousseff (que llegó con mínimos niveles de aprobación de su gobierno) fue apoyado por parte de la llamada clase media tradicional (pequeña y mediana burguesía consolidada) y la llamada nueva clase media (mayoritariamente el proletariado que mejoró profundamente sus condiciones de vida). Pero las demandas de quienes organizan estos grupos sólo en parte coinciden con la agenda neoliberal. Particularmente la coincidencia se apoya en la reducción de impuestos en el caso de la "clase media tradicional".

$16 \mathrm{El}$ caso de Ecuador merece una mención aparte respecto a cómo ubicarlo en este panorama latinoamericano dada la complejidad de su proceso político actual. Lenín Moreno ganó las elecciones en balotaje por un estrecho margen el 2 abril de 2018 de la mano del partido político Alianza País liderado por Rafael Correa. Moreno fue elegido por el partido para suceder a Correa en las elecciones presidenciales, dado que la Constitución ya no le permitía volver a postularse. El programa político que Moreno anunciaba en campaña electoral se anclaba en el programa de la Revolución Ciudadana, tal como se denominó el proceso político liderado por Correa. Su eslogan de campaña fue el "cambio en la continuidad”. Sin embargo, al cabo de una semana de asumir la presidencia el 24 de mayo de 2018, Moreno inició de forma instantánea una "descorreización” (Ramírez Gallegos, 2018) del proyecto político a través de una rearticulación con sectores de derecha (banqueros, partidos políticos tradicionales, grupos mediáticos monopólicos). Esta descorreización operó a través del anuncio de distintas decisiones políticas como el acercamiento con el FMI y la convocatoria a una consulta popular - 4 de febrero de 2018- para inhabilitar en próximas contiendas electorales la candidatura de Rafael Correa, quien para ese momento contaba con un robusto apoyo popular.

17 El caso de Chile es más complejo porque los gobiernos de Michelle Bachelet expresaron más un progresismo liberal y de continuidad con las políticas de la Concertación de los años noventa, que una ruptura nacional popular.

18 Hemos optado por descartar los calificativos de izquierda y derecha por considerar que dicho clivaje no logra capturar a cabalidad las orientaciones que asumen los gobiernos, tanto los del giro postneoliberal, como los actuales que lideran la reiniciativa neoliberal.

19 Esta ley, que entró en vigencia en agosto 2018, está orientada a bloquear la capacidad estatal para obtener ingresos y capturar renta a través de la condonación de deudas a capitales privados y la reducción de impuestos a los grandes grupos económicos.

20 Audición de Kurt Tidd ante la Comisión de Servicios de las Fuerzas Armadas del Senado de Estados Unidos, 15 de febrero de 2018.

21 "El vicepresidente de Brasil se reúne con Pence y rechaza una intervención militar en Venezuela”, Nodal, 9 de abril de 2019. https://www.nodal.am/2019/04/el-vicepresidente-de-brasil-se-reune-con-pence-y-rechaza-una-intervencion-militar-en-venezu ela/ 